\title{
Effects on Average Orifice Diameter of Hollow-Cone Nozzles due to Orifice Wear
}

\author{
Akshay Kumar Singh*, Nishanth M. Stanly, Pankaj Malkani and K. R. Asha \\ ICAR-Indian Agricultural Research Institute, New Delhi-110012, India \\ *Corresponding author
}

\begin{tabular}{|c|}
\hline Keywords \\
\hline $\begin{array}{l}\text { Circular-cone } \\
\text { orifice, Wear, } \\
\text { Average orifice } \\
\text { diameter, } \\
\text { Microscopic image }\end{array}$ \\
\hline Article Info \\
\hline $\begin{array}{l}\text { Accepted: } \\
\text { 07 November } 2019 \\
\text { Available Online: } \\
10 \text { December } 2019\end{array}$ \\
\hline
\end{tabular}

A B S T R A C T
Pesticides spray nozzle is an essential component to the sprayers of almost all kinds. Orifice tip of nozzle emits the spray solution into finer droplets of desired size and spectrum and sprayed on agricultural field crops. Hollowcone type nozzles fitted with circular cone orifices are very effective to spray finer droplets due to swirling action of swirl plate. However, these nozzles fail to maintain their droplets size and spray pattern due to wear which results an increase in average orifice diameter (AOD) of nozzle. Three types of hollow-cone nozzles with circular orifices made of plastic, stainless steel and ceramic were studied to investigate the effect on the AOD of orifices under microscopic image analysis due to wear. The experiment was conducted at three different spray pressures of 3.5, 7.0 and $10.5 \mathrm{~kg} \mathrm{~cm}^{-2}$, respectively. Statistical analysis revealed that the orifice plates made of ceramic materials were the most effective as compared to stainless steel and plastic orifices studied.

\section{Introduction}

A healthy crop production can lead the agricultural sector into the pace of a country's economy. With reference to India, the country holds $13.9 \%$ share of agricultural sector into the India's GDP growth. Mahatma Gandhi said, "There is a moral death on the both sides of the sufficient". The analogy soundly stands with the pesticide application on the agricultural field crops in the form of spray droplets. If there is a poor pesticide spray (insufficient) the standing crop on the field shall become the prey of pests. On the other hand, over application of pesticide (more than sufficient) causes harmful effects in many ways like soil pollution, increase in cost of production etc. Like many other factors, spraying also influences the plant growth. An accurate quantity of spray may results of 
higher crop productivity and the quality of field produce.

In Indian perspective, the nature of pesticide application is as skewed as diversified the country, India, is. The scientific use of pesticide is lowest $(0.57 \mathrm{~kg} / \mathrm{ha})$ in India among the developed and most of the developing nations (Japan - $11.0 \mathrm{~kg}$, Netherlands- $9.4 \mathrm{~kg}$, Republic of Korea $6.6 \mathrm{~kg}$, France-4.6 kg, Italy - $4.17 \mathrm{~kg}$, Germany-2.5 kg, Austria -2.4 kg, USA- $2.25 \mathrm{~kg}$ and Pakistan - $1.3 \mathrm{~kg}$ per hectare) (Bhatnagar, 2014). This may be noted that the US is known as the most health conscious country, but the scientific use of pesticide is nearly four times higher than that of India and productivity of many crops in that country is much higher than India.

On the other hand, India has been seen with an excess use of pesticide spray in some crops which do not support in plant growth but plays havoc to the environment as well as the life of a mankind. This excess use of pesticide takes place by two means - thinking that if a little is better a lot more will be the best and due to the ignorance of wear on the orifice of the nozzle. An orifice tip-material is the ultimate component which holds the in-built pressure and emits liquid into the form of spray droplets. Orifice plate of a nozzle works best up to a certain time of usage which is highly dependent on the flow rate of the orifice.

Although some nozzle manufacturers recommend replacement of old nozzles with new nozzle when the increase of flow rate of old nozzle reaches out $10 \%$ of the initial flow rate, many pesticide applicators tend to use nozzles longer. An orifice is assumed to be worn-out as the flow rate exceeds $15 \%$ of the initial flow rate of that orifice when operated at a particular pressure (Krishnan et al., 2004).

From the pre-independence era of India, studies were geared up on the wear of nozzles in the world. Since then, many studies have been taken place. Many researchers (Friesen, 1984; Doll et al., 1991; Ozkan 1992; Womac 2000; Duvnjak et al., 1998) studied spray distribution pattern across the swath and stream droplets size. Others (Reichard et al., 1991; Zhu et al., 1995; Sukumaran et al., 2012) investigated the effect of flow rate with the usage of time of nozzles. The study of wear behaviour was nascent in India which comprises materials of construction, operating pressures, flow rates and physical hardness of the spray solution (Sanchu et al., 2013). The long run wear test was carried out with an abrasive material (china clay powder) mixed with the fresh water having minimum foreign matter (Anon. 1998).

Therefore, study was performed to investigate the effect of wear on circular-cone orifice plates of hollow-cone nozzles made of plastic, stainless steel and ceramic materials. Hollowcone nozzles are most suitable in the pesticide spray as they produce finer droplets and used with whirl devices which results an appropriate pressure drop (Kepner \& Bainer, 2005). All three orifice materials were studied under the long run wear test at operating spray pressures of $3.5,7.0$, and $10.5 \mathrm{~kg} \mathrm{~cm}$, respectively. The factors that causes wear are the operating pressure, material of construction of orifice of nozzle-tip, shape and size of the orifice and the concentration of the spray solution (Zhu et.al., 1995). Researchers have investigated wear rates on nozzles having various shape and size in which the percentage change in flow rate has been used as an indicator to predict the wear rate. They compared flow rates of used nozzles with the flow rates of new nozzles of the same size and type and stated that as the best way to predict the wear on the orifice plates (Krishnan et al., 2004). Under this study, the effect of wear on the average orifice diameter (AOD) was observed under microscope and the statistical interference was drawn. 


\section{Materials and Methods}

Circular-cone orifices made of plastic and stainless steel are frequently used to spary agrochemical pesticides commercially whereas the use of ceramic has recently started. Hence, all three materials were used for the study. Bunch of hollow-cone nozzles made of plastic, stainless steel and ceramic with circular orifices were randomly selected from the inventory of Agricultural Research and Development Foundation (ARDF), American Springs and Pressing Works (ASPEE) in which a set of three nozzles of each material were selected with similar flow rates at initial with minimum variations. The nozzles were first washed with fresh water for 15 minutes and then transferred to the wear test rig for long run wear test (Singh et al., 2017). Initial and final oifice diameters of the recorded through the microscope (Figure 1).

New and worn-out orifice samples were put under the microspore and their respective images were captured through computer based software. Average orifice diameter (AOD) was measured by drawing a number of virtual cords passing through the center of the orifice. In order to locate the center of the orifice, a virtual XY-plane was put below the sample containing overall dimension of each orificetip material. The sample size was small and the treatment effect was to be known between two variables i.e. average orifice diameter (AOD) before the wear test $\left(\mathrm{D}_{0}\right)$ and after the wear test $\left(\mathrm{D}_{15}\right)$. Student's t-test was used to determine the effect of wear on orifice diameter of hollow cone nozzles made of plastic, stainless steel and ceramic.

\section{Results and Discussion}

Since all the nozzles were envisaged to be undergone some material loss all around their orifice area due to wear under the long run wear test at different pressures. Table 2 clears the pioneer picture that a considerable percentage increase of average orifice diameter has occurred even testing nozzles at relatively low pressure. Percentage increase of orifice diameter has been recognized keep on increasing with increase of spraying pressure in nozzles having plastic and stainless steel as tip-materials whereas ceramic nozzle-tips have shown very small variations in fractions at all spraying pressures.

Plastic tip-material has undergone 7.31, 14.53 and 28.43 per cent of increase in average orifice diameter after $40 \mathrm{~h}$ of wear test at spray pressures of $3.5,7.0$, and $10.5 \mathrm{~kg}-\mathrm{cm}^{-2}$, respectively (Table 1). Whereas, Stainless steel has shown 4.44, 8.15, and 15.95 per cent of increase of average orifice diameter at 3.5,

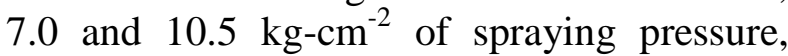
respectively. Orifice tips made of ceramic material has shown the least percentage increase in average orifice diameter with the amount of 1.00, 1.67 and 2.92 per cent of increase of average orifice diameter at 3.5, 7.0 and $10.5 \mathrm{~kg}_{-} \mathrm{cm}^{-2}$ of spraying pressure respectively. Therefore, it was clear that material loss has occurred through orifice wall at all working pressures of spraying during the long run wear test till the nozzle-tips became worn-out.

Figure 2 showed the deterioration during the wear test of orifice tips of hollow-cone type nozzles used in agrochemical spraying. Orifice tips made of plastic, stainless steel and ceramic materials at spray pressures of 3.5, 7.0 and $10.5 \mathrm{~kg} \mathrm{~cm}^{-2}$, respectively. All materials have shown an increase in average diameter of circular orifice. The pattern of removal of material is almost circular with minor dimensional variations along the periphery of the circular orifice but the inner surface around the orifice has shown a considerable loss of material. This phenomenon may be seen where nozzle-tips have displayed a loss of material after exceeding the discharge rate 
15 per cent of the initial discharge rate in respective orifice tip-materials under the pressure of $3.5 \mathrm{~kg}^{-\mathrm{cm}^{-2}}$ of spraying. This surface deterioration has occurred all around the periphery of the circular orifice area in plastic, stainless steel and ceramic because the hollow-cone nozzles are generally used with whirl devices which creates a centrifuge effect before emitting the spray liquid out in the form of spray. The effect has been seen more when the pressure is higher.

An image analysis of hollow-cone nozzles having plastic, stainless steel and ceramic as orifice tip materials under the microscopic visual inspection before and after the long run wear test at the pressure of $3.5 \mathrm{~kg}-\mathrm{cm}^{-2}$ of spraying. A difference of $88.19 \mu \mathrm{m}$ has been recorded in the average orifice diameter which results 7.31 per cent of increase in orifice size of same material of plastic. The difference is of $93.33 \mu \mathrm{m}$ has recorded in circular orifice having stainless steel as tip-material which leads an increase of 6.66 per cent of average orifice size of the same material. Same material has shown an increase of 8.00 per cent in circular orifice tip-material of ceramic with the difference of $80 \mu \mathrm{m}$ in average orifice size. Figure 2 has shown image analysis when all three testing nozzles having plastic, stainless steel and ceramic as tip-material were mounted under a long run wear test at the pressure of $7.0 \mathrm{~kg}-\mathrm{cm}^{-2}$ of spraying.

Plastic tip-material has shown a percentage increase of 9.08 per cent in average orifice diameter with the difference of $114.52 \mu \mathrm{m}$ in the average orifice size which is 1.24 times higher than the percentage increase occurred in plastic tip-material at $3.5 \mathrm{~kg} \mathrm{~cm}^{-2}$ of spraying. Stainless steel has been recorded with $114.16 \mu \mathrm{m}$ of difference in average orifice size which leads to a percentage increase of 8.15 per cent in average orifice diameter and 1.22 times higher with respect to the same stainless steel tip-material when tested at the pressure of $3.5 \mathrm{~kg} \mathrm{~cm}$ of spraying. Ceramic tip-material has seen with a difference of $100 \mu \mathrm{m}$ in average orifice size and a percentage increase of 8.33 per cent in average orifice diameter which is just 1.04 times higher when the same material was tested at $3.5 \mathrm{~kg}-\mathrm{cm}^{-2}$ of spraying pressure.

Table.1 Percentage increase of average orifice diameters after $40 \mathrm{~h}$ of wear test

\begin{tabular}{|c|c|c|c|c|}
\hline $\begin{array}{c}\text { Pressure, } \\
\mathbf{k g ~ c m}^{-2}\end{array}$ & $\begin{array}{c}\text { Material of } \\
\text { orifice plate }\end{array}$ & \multicolumn{2}{|c|}{ Average Orifice Diameter (AOD), $\boldsymbol{\mu m}$} & $\begin{array}{c}\text { Percentage } \\
\text { increase of AOD } \\
\text { after 40 hours }\end{array}$ \\
\cline { 3 - 5 } & & $\mathbf{D}_{\mathbf{0}}$ & $\mathbf{D}_{\mathbf{1 5}}$ & 7.31 \\
\hline \multirow{3}{*3.5}{} & Plastic & 1205.98 & 1294.17 & 4.44 \\
\cline { 2 - 5 } & Stainless Steel & 1400.42 & 1493.75 & 1.00 \\
\cline { 2 - 5 } & Ceramic & 1000.00 & 1080.00 & 14.53 \\
\hline \multirow{2}{*}{$\mathbf{7 . 0}$} & Plastic & 1205.98 & 1315.50 & 8.15 \\
\cline { 2 - 5 } & Stainless Steel & 1400.42 & 1514.58 & 1.67 \\
\cline { 2 - 5 } & Ceramic & 1200.00 & 1300.00 & 28.43 \\
\hline \multirow{2}{*}{$\mathbf{1 0 . 5}$} & Plastic & 1205.98 & 1334.50 & 2.95 \\
\hline & Stainless Steel & 1400.42 & 1540.00 & 2.92 \\
\hline
\end{tabular}


Table.2 Statistical analysis of orifice nozzles at various spray pressures

\begin{tabular}{|c|c|c|c|c|c|c|c|c|c|c|c|c|c|c|c|c|c|c|c|c|}
\hline \multirow{2}{*}{$P_{1}=3.5 \mathrm{~kg}_{-}-\mathrm{cm}^{-2}$} & \multicolumn{2}{|c|}{ Plastic } & \multicolumn{2}{|c|}{ Stainless Steel } & \multicolumn{2}{|c|}{ Ceramic } & \multirow{2}{*}{$P_{2}=7.0 \mathrm{~kg}-\mathrm{cm}^{-2}$} & \multicolumn{2}{|c|}{ Plastic } & \multicolumn{2}{|c|}{ Stainless Steel } & \multicolumn{2}{|c|}{ Ceramic } & \multirow{2}{*}{$P_{3}=10.5 \mathrm{~kg}_{-} \mathrm{cm}^{-2}$} & \multicolumn{2}{|c|}{ Plastic } & \multicolumn{2}{|c|}{ Stainless Steel } & \multicolumn{2}{|c|}{ Ceramic } \\
\hline & $A_{m}$ & $\mathbf{B}_{\mathrm{m}}$ & $\mathbf{A}_{\mathrm{m}}$ & $\mathbf{B}_{\mathrm{m}}$ & $A_{\mathrm{m}}$ & $\mathbf{B}_{\mathrm{m}}$ & & $A_{m}$ & $\mathbf{B}_{\mathrm{m}}$ & \begin{tabular}{l|l}
$\mathbf{A}_{\mathrm{m}}$ & \\
\end{tabular} & $\mathbf{B}_{\mathrm{m}}$ & \begin{tabular}{|l|}
$A_{m}$ \\
\end{tabular} & $\mathbf{B}_{\mathrm{m}}$ & & \begin{tabular}{|l|l}
$A_{m}$ \\
\end{tabular} & $\mathbf{B}_{\mathrm{m}}$ & $A_{m}$ & $\mathbf{B}_{\mathrm{m}}$ & $A_{m}$ & $\mathbf{B}_{\mathrm{m}}$ \\
\hline Observations & 12 & 12 & 12 & 12 & 12 & 12 & Observations & 12 & 12 & 12 & 12 & \begin{tabular}{|r|}
12 \\
\end{tabular} & 12 & Observations & 12 & 12 & 12 & \begin{tabular}{|l|}
12 \\
\end{tabular} & 12 & 12 \\
\hline Mean & 1205.917 & \begin{tabular}{|l|}
1294.167 \\
\end{tabular} & 1400.417 & 1493.75 & 1000.5 & 1080.833 & Mean & 1205.917 & 1316.25 & 1400.417 & 1514.58 & 1200.3 & 1300 & Mean & 1205.917 & 1335.75 & 1400.417 & 1335.75 & 800.67 & 871.083 \\
\hline SD & 8.596627 & \begin{tabular}{|l|}
11.044 \\
\end{tabular} & 2.073451 & 3.10789 & 2.2361 & 8.211212 & SD & 8.596627 & 9.076673 & \begin{tabular}{|l|l|}
6.556829 & \\
\end{tabular} & 11.3735 & \begin{tabular}{|l|l|}
2.6672 \\
\end{tabular} & 7.385459 & SD & 2.718492 & 3.74473 & 2.073451 & 3.74473 & 3.114 & 3.232182 \\
\hline df & \multicolumn{2}{|c|}{22} & \multicolumn{2}{|c|}{\begin{tabular}{l|}
22 \\
\end{tabular}} & \multicolumn{2}{|c|}{22} & df & \multicolumn{2}{|c|}{22} & \multicolumn{2}{|c|}{22} & \multicolumn{2}{|c|}{22} & df & \multicolumn{2}{|c|}{22} & \multicolumn{2}{|c|}{22} & \multicolumn{2}{|c|}{22} \\
\hline $\mathrm{t}$ Stat or $|\mathrm{t}|$ & \multirow{2}{*}{\multicolumn{2}{|c|}{$\begin{array}{c}21.84 \\
2.09 \mathrm{E}-16\end{array}$}} & \multirow{2}{*}{\multicolumn{2}{|c|}{$\frac{44.56}{4.63 \mathrm{E}-23}$}} & \multirow{2}{*}{\multicolumn{2}{|c|}{$\frac{32.70}{3.80 \mathrm{E}-20}$}} & $t$ Stat or $|t|$ & \multirow{2}{*}{\multicolumn{2}{|c|}{$\begin{array}{c}30.57 \\
1.616 \mathrm{E}-19\end{array}$}} & \multirow{2}{*}{\multicolumn{2}{|c|}{$\frac{30.12}{2.220 \mathrm{E}-19}$}} & \multicolumn{2}{|c|}{44.01} & $\mathrm{t}$ Stat or $|\mathrm{t}|$ & \multicolumn{2}{|c|}{47.96} & \multicolumn{2}{|c|}{29.67} & \multicolumn{2}{|c|}{54.35} \\
\hline Pvalue & & & & & & & Pvalue & & & & & 6.07 & $6 \mathrm{E}-23$ & Pvalue & $9.30 \mathrm{E}$ & 24 & $3.09 \mathrm{I}$ & -19 & & $8 \mathrm{E}-25$ \\
\hline t Crit & \multicolumn{2}{|c|}{2.42} & \multicolumn{2}{|c|}{2.42} & \multicolumn{2}{|c|}{2.42} & t Crit & \multicolumn{2}{|c|}{2.42} & 2.42 & & & .42 & t Crit & 2.4 & & 2.4 & 12 & & 2.42 \\
\hline Result & & 5 & $\mathrm{~S}$ & & & $\mathrm{~S}$ & Result & 5 & 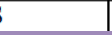 & $\mathrm{S}$ & & & $\mathrm{S}$ & Result & $\mathrm{S}$ & & S & & & $\mathrm{S}$ \\
\hline
\end{tabular}

Fig.1 Microscopic image analysis

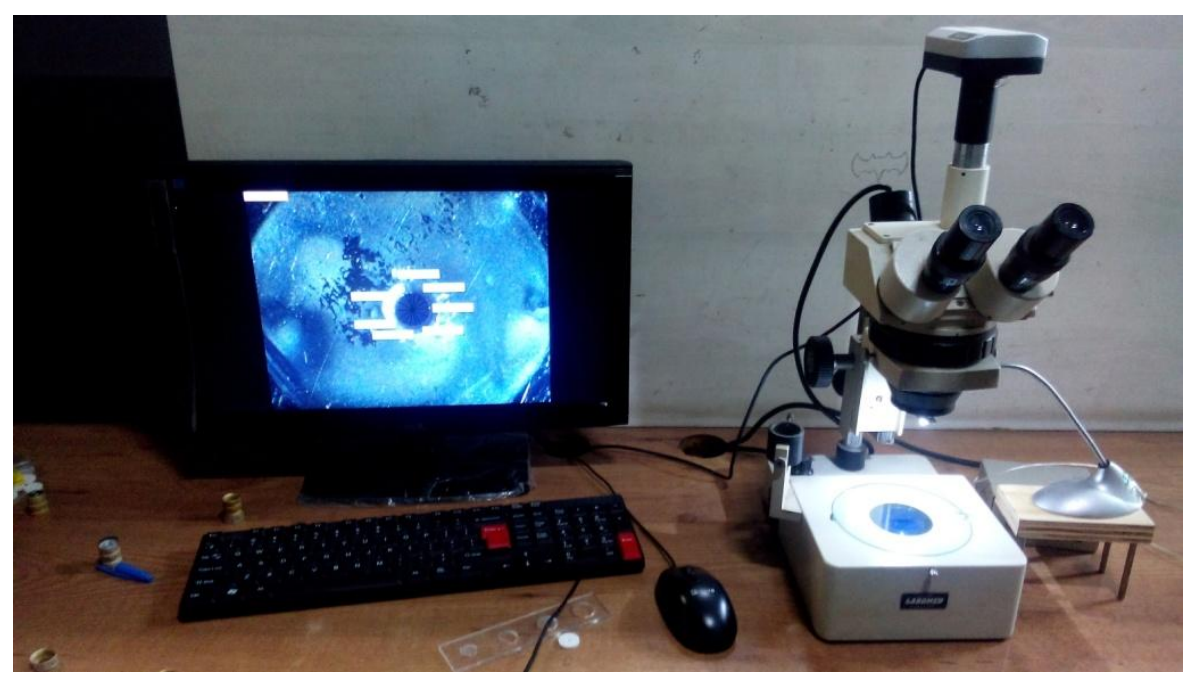


Fig.2 Change in average orifice diameter (AOD) of different orifice materials at various spray pressure

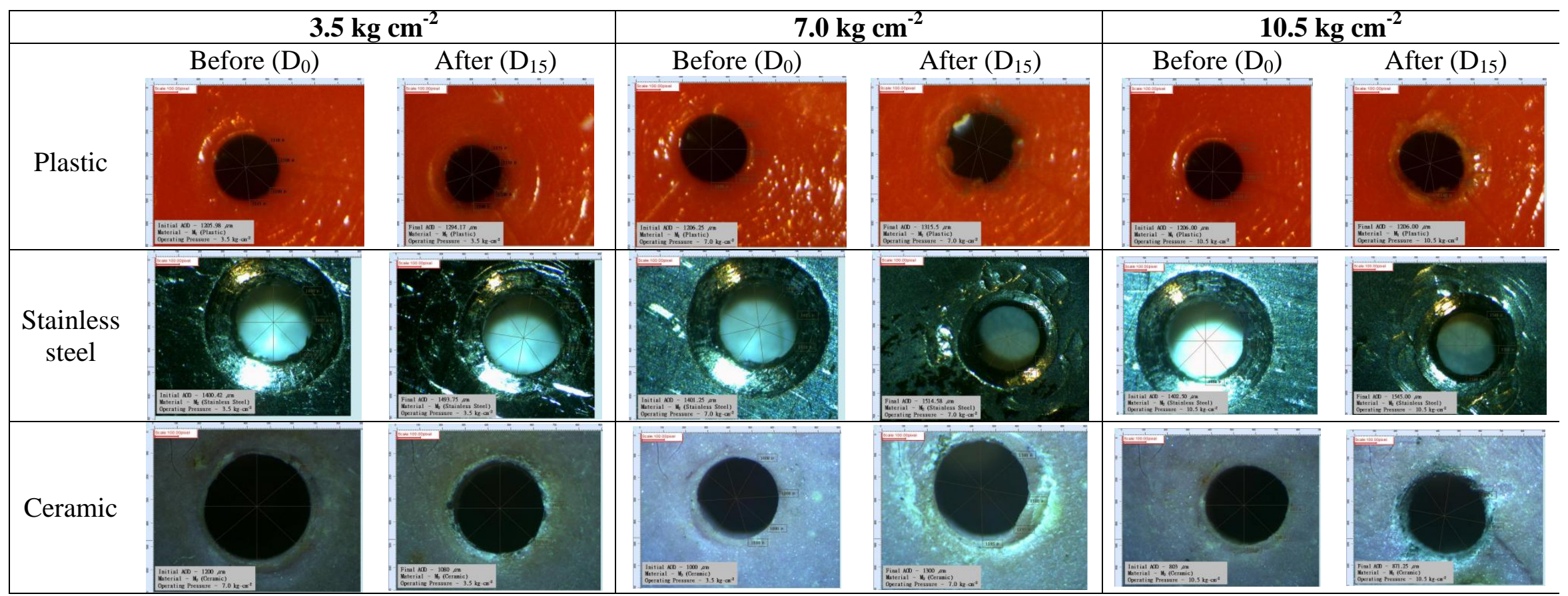


Images shown in Figure 2 deals with the increase of average orifice diameter of all tested material having plastic, stainless steel and ceramic as tip-material after long run wear test at the pressure of $10.5 \mathrm{~kg}-\mathrm{cm}^{-2}$ of spraying. Plastic tip-material has recorded with a percentage increase of 10.66 per cent in average orifice diameter with the difference of $133.52 \mu \mathrm{m}$ of average orifice size which is 1.45 and 1.17 times higher, in terms of percentage increase of average orifice diameter, than the same plastic tip-materials when tested at the pressure of 3.5 and $7.0 \mathrm{~kg}$ $\mathrm{cm}^{-2}$ of spraying respectively. Stainless steel has shown a difference in average orifice size of $139.58 \mu \mathrm{m}$ and percentage increase of 9.97 per cent which is 1.50 and 1.22 times higher than when same tip-material of stainless steel was tested at 3.5 and $7.0 \mathrm{~kg} \mathrm{~cm}^{-2}$ of spraying pressure. Ceramic has shown a difference of $70 \mu \mathrm{m}$ with the percentage increase of $8.75 \%$ of average orifice diameter which is just 1.09 and 1.05 times higher than the same ceramic tip-material when tested at 3.5 and $7.0 \mathrm{~kg} \mathrm{~cm}^{-2}$ of spraying pressure, respectively. A student's t-test: Two-Sample Assuming Equal Variance was performed to find the statistical significance (at $1 \%$ level of significance) of increase of average orifice diameter of different hollow-cone nozzles with circular orifice having plastic, stainless steel and ceramic as orifice tip materials when each tipmaterial tested at different spraying pressures of $3.5,7.0$, and $10.5 \mathrm{~kg}-\mathrm{cm}^{-2}$ respectively. Data sets were analyzed using computer assisted software.

Initial and final orifice diameters were denoted by letter $A$ and letter $B$ respectively and $A_{m}$ and $B_{m}$ were their respective mean values. Table 2 has shown a significant difference (at $1 \%$ level of significance) in the average orifice diameters of new and worn out nozzles with different tip-materials (plastic, stainless steel and ceramic) at $3.5 \mathrm{~kg}-\mathrm{cm}^{-2}$ of spraying pressure. The effect of the difference of average orifice diameter of new and worn out nozzles of all three materials i.e. plastic, stainless steel and ceramic and found significant (1\% level of significance) at 7.0 and $10.5 \mathrm{~kg}_{-} \mathrm{cm}^{-2}$ respectively. Material of construction of orifice plate has significant effect on wear rate with the usage of time and found minimum in ceramic plate followed by stainless steel and plastic. Orifice plate diameter of all nozzles increases at significant level at all pressures of spraying. Hollow-cone nozzles with ceramic orifice plate has been found more useful for both lower and higher pressure of liquid spraying in comparison with either plastic or stainless steel orifice plate. In regards of percentage increase of average orifice diameter, this is clear that the variations are reported minimum in case of ceramic tip-material as compare to either plastic or stainless steel.

\section{Acknowledgements}

Authors express their thanks to Agricultural Research and Development Foundation (ARDF), American Springs and Pressing Works (ASPEE) for providing the research facilities and the in-process support for the entire crew members of the organization.

\section{References}

Appah S, Wang P, Ou M X, Gong C, Jia W D. Review of electrostatic system parameters, charged droplets characteristics and substrate impact behavior from pesticides spraying. Int J Agric \& Biol Eng, 2019; 12(2): 1-9.

ASAE Standards. Procedure for measuring spray nozzle wear rate. St. Joseph, Mich.: ASAE, 1998; S471.

Ballal K, Krishanan P, Kemble J, Issler A. Nozzle selection and replacement based on nozzle wear analysis. Agricultural Engineering: Abstract, 1998; 29(1): 795-804. 
Bindra, O S, Singh H. Pesticide Application Equipment, New Delhi: Oxford and IBH publication, 1977.

Devi P I, Thomas J, Raju R K. Pesticide consumption in India: A spatiotemporal analysis. Agricultural Economics Research Review, 2017; 30(1): 163-172.

Indian standards. Crop protection equipment Foot sprayer - Specification (4th revision). New Delhi: Bureau of Indian Standards, 1995; 3552.

Kapner, R A, and Bainer R. Principles of Farm Machinery, 3rd Edition. New Delhi:CBS publishers and distributor, 2005.

Krishnan P, Evans T, Ballal K, Kemble L J. Scanning electron microscope studies of new and used fan nozzles for agricultural sprayers. Applied Engineering in Agriculture, 2004; 20(2): 133-137.

Ozkan H E, Reichard D L, Ackerman K D. Effect of orifice wear on spray pattern from fan nozzles. Transactions of the ASAE, 1992; 35(4): 1091-1096.

Reichard D L, Ozkan H E, Sweeney J S. Droplet size distribution across the fan patterns of new and worn nozzles. Transactions of the ASAE, 1992; 35(4): 1097-1102.

Reichard, D L, Ozkan H E, Fox R D. Nozzle wear rates and test procedure. Transactions of the ASAE, 1991; 34(6): 2309-2016.
Shetty P K, Hiremath, M S, Sreeja K G. Farmer seducation and perception on pesticide use and crop economies in Indian Agriculture. Journal of Experimental Sciences, 2010; 1(1): 38.

Singh A K, Bhatt Y C. Wear on circular orifice plate of hollow-cone type agrochemical spray nozzles. Agricultural Engineering International: CIGR Journal, 2018; 20(3): 78-84.

Slocombe J W, Sharda A. Agricultural spray nozzles: selection and sizing. Application technology Series: KSTATE Research and Extension, 2015; pp: $1-12$.

Sukumaran, S, Manes G S, Singh S K. Effect of spraying pressure and usage on discharge rate and wear of hollowcone nozzles having different nozzle tip material. Journal of Agricultural Engineering, 2013; 50(1): 1-8.

Sztachó-Pekáry I. The effects of fan nozzles orifice wear on flow rate and spray pattern. Progress in Agricultural Engineering Sciences, 2004 (1): 7-29.

Womac A R. Quality controls of standardized reference spray nozzles. Transactions of the ASAE, 2000; 43(1): 47-56.

Zhu H, Reichard D L, Ozkan H E, Brazee R D, Fox R D. Mathematical model to predict wear rate of nozzles with elliptical orifices. Transactions of the ASAE, 1995; 38(5): 1297-1303.

\section{How to cite this article:}

Akshay Kumar Singh, Nishanth M. Stanly, Pankaj Malkani and Asha, K. R. 2019. Effects on Average Orifice Diameter of Hollow-Cone Nozzles due to Orifice Wear. Int.J.Curr.Microbiol.App.Sci. 8(12): 667-674. doi: https://doi.org/10.20546/ijcmas.2019.812.087 